\title{
Development and Pilot Trial Results of Stochastic Targeted (STAR) Glycemic Control in a Medical ICU
}

\author{
Liam M. Fisk ${ }^{*}$, Aaron J. Le Compte", Geoffrey M. Shaw ${ }^{* *}$, Sophie Penning ${ }^{* * *}$, Thomas Desaive ${ }^{* * *}$, J. Geoffrey Chase* \\ * Department of Mechanical Engineering, University of Canterbury \\ New Zealand (phone: +64-3-364-2596, e-mail: geoff.chase@canterbury.ac.nz) \\ ** Department of Intensive Care, Christchurch Hospital, New Zealand \\ *** Centre for Cardiovascular Research, University of Liege, Belgium
}

\begin{abstract}
Accurate glycemic control (AGC) is difficult due to excessive hypoglycemia risk. Stochastic TARgeted (STAR) glycemic control forecasts changes in insulin sensitivity to calculate a range of glycemic outcomes for an insulin intervention, creating a risk framework to improve safety and performance. An improved, simplified STAR framework was developed to reduce light hypoglycemia and clinical effort, while improving nutrition rates and performance. Blood glucose (BG) levels are targeted to $80-145 \mathrm{mg} / \mathrm{dL}$, using insulin and nutrition control for 1-3 hour interventions. Insulin changes are limited to $+3 \mathrm{U} /$ hour and nutrition to $\pm 30 \%$ of goal rate (minimum $30 \%$ ). All targets and rate change limits are clinically specified and generalizable. Clinically validated virtual trials were run using clinical data from 371 patients $(39,841$ hours) from the SPRINT cohort. Cohort and per-patient results are compared to clinical SPRINT data. Performance was measured as time within glycemic bands, and safety by patients with severe $(\mathrm{BG}<40 \mathrm{mg} / \mathrm{dL})$ and mild $(\% \mathrm{BG}<72 \mathrm{mg} / \mathrm{dL})$ hypoglycemia. Pilot trial results from the first 10 patients $(1,458$ hours) are included to support the in-silico findings. In both virtual and clinical trials, mild hypoglycemia was below $2 \%$ versus $4 \%$ for SPRINT. Severe hypoglycemia was reduced from 14 (SPRINT) to 6 (STAR), and 0 in the pilot trial. BG results tighter than SPRINT clinical data, with $91.6 \%$ BG within the specified target $(80-145 \mathrm{mg} / \mathrm{dL})$ in virtual trials and $89.4 \%$ in pilot trials. Clinical effort (measurements) was reduced from 16.1/day to 11.8/day (13.5/day in pilot trials). This STAR framework provides safe, accurate glycemic control with significant reductions in hypoglycemia and clinical effort due to stochastic forecasting of patient variation - a unique risk-based approach. Initial pilot trials validate the in silico design methods and resulting protocol, all of which can be generalized to suit any given clinical environment.
\end{abstract}

Keywords: Decision support and control; Decision support systems for the control of physiological and clinical variables

\section{INTRODUCTION}

Stress-induced hyperglycemia is a significant issue in critical care, affecting up to $30-50 \%$ of patients and increasing morbidity and mortality (McCowen et al., 2001, Krinsley, 2004). Controlling glycemia has proved difficult due to the associated risk of hypoglycemia when highly dynamic patients are treated with exogenous insulin (Griesdale et al., 2009). Both extremes, as well as glycemic variability, have been independently linked to increased morbidity and mortality (Bagshaw et al., 2009, Egi et al., 2006, Krinsley, 2008), creating a difficult clinical problem safely and effectively regulating glycemia to a physiologically and clinically safe range.

Accurate glycemic control (AGC) can mitigate these outcomes(Chase et al., 2008b, Van den Berghe et al., 2001), but has proven difficult to achieve safely and consistently (Casaer et al., 2011). Only one study (Chase et al., 2008b) reduced both mortality and hypoglycemia. However, the higher nursing workloads due to high density glucose readings are impractical in many units (Mackenzie et al., 2005, Aragon, 2006). Hand-held glucometers are easier for measurement, but their larger errors can add additional difficulty for some AGC protocols. Finally, clinical compliance determines much of the efficacy of any AGC method, with quality of glycemic control thus also limited by the confidence and compliance of nursing staff (Aragon, 2006, Chase et al., 2008a). All of these issues interact with the inherent inter- and intra- patient metabolic variability (Chase et al., 2011) to exacerbate the difficulty of achieving good control. Hence, glycemic control targets are often raised to mitigate these factors and avoid hypoglycaemia as a best outcome compromise, despite the physiological and clinical evidence on the negative impact of even moderate hyperglycemia (McCowen et al., 2001, Krinsley, 2004).

Directly quantifying and managing hyperglycemic and hypoglycemic risk as a function of inter- and intra- patient metabolic variability can leverage AGC benefits and minimize risk of unintended harm. STAR (Stochastic TARgeted) is a model-based AGC framework that can be implemented across a range of clinical scenarios and approaches, and uses dynamic and stochastic models to regulate BG levels, workload and patient safety within a predefined risk management approach. STAR uses stochastic forecasting of a patient's potential metabolic variability(Lin et al., 2008) in conjunction with a clinically validated mathematical model (Lin et al., 2011, Chase et al., 2010b) to determine optimal insulin and nutrition treatment 
combinations with specified risks of moderate hyper- and hypo- glycemia. In essence, it is a patient-specific approach to manage inter- and intra- patient variability that overlaps the glycemic outcome range for a given intervention with a clinically specified desired glycemic range. It thus provides both control and a clinically specified risk of moderate hypoglycemia. Hence, STAR provides a framework of models and methods to manage intra- and inter- patient variability to mitigate the significant difficulty and risk seen in current glycemic control approaches (Griesdale et al., 2009, Chase et al., 2011).

This paper presents an enhanced and simplified STAR protocol, and its development and optimization using virtual trials. Specific focus is placed on reducing mild hypoglycemia $(\mathrm{BG}<72 \mathrm{mg} / \mathrm{dl}$ ) and its associated risk (Bagshaw et al., 2009), while maintaining glycemia in bands with the best evidence for improved outcome. Protocol simplicity and transparency are optimized to increase compliance.

\section{METHODS}

\subsection{Model}

The clinically validated Intensive Care Insulin-NutritionGlucose (ICING) metabolic model was used to simulate the fundamental metabolic dynamics (Lin et al., 2011). Table I lists the population constants of the model defined in Equations 1-6.

$$
\begin{aligned}
& \dot{\mathrm{G}}=-\mathrm{p}_{\mathrm{G}} \mathrm{G}(\mathrm{t})-\mathrm{S}_{\mathrm{I}} \mathrm{G}(\mathrm{t}) \frac{\mathrm{Q}(\mathrm{t})}{1+\alpha_{\mathrm{G}} \mathrm{Q}(\mathrm{t})}+\frac{\mathrm{P}(\mathrm{t})+\mathrm{EGP}_{\mathrm{b}}-\mathrm{CNS}+\mathrm{PN}(\mathrm{t})}{\mathrm{v}_{\mathrm{g}}} \\
& \dot{\mathrm{I}}=-\frac{\mathrm{n}_{\mathrm{L}} \mathrm{I}(\mathrm{t})}{1+\alpha_{\mathrm{I}} \mathrm{I}(\mathrm{t})}-\mathrm{n}_{\mathrm{K}} \mathrm{I}(\mathrm{t})-(\mathrm{I}(\mathrm{t})-\mathrm{Q}(\mathrm{t})) \mathrm{n}_{\mathrm{I}}+\frac{\mathrm{u}_{\mathrm{ex}}(\mathrm{t})}{\mathrm{V}_{\mathrm{I}}}+\left(1-\mathrm{x}_{\mathrm{L}}\right) \frac{\mathrm{u}_{e n}(\mathrm{G})}{\mathrm{V}_{\mathrm{I}}} \\
& \dot{\mathrm{Q}}=(\mathrm{I}(\mathrm{t})-\mathrm{Q}(\mathrm{t})) \mathrm{n}_{\mathrm{I}}-\mathrm{n}_{\mathrm{C}} \frac{\mathrm{Q}(\mathrm{t})}{1+\alpha_{\mathrm{G}} \mathrm{Q}(\mathrm{t})} \\
& \dot{\mathrm{P}}_{1}=-\mathrm{d}_{1} \mathrm{P}_{1}+\mathrm{P}(\mathrm{t}) \\
& \dot{\mathrm{P}}_{2}=-\min \left(\mathrm{d}_{2} \mathrm{P}_{2}, \mathrm{P}_{\max }\right)+\mathrm{d}_{1} \mathrm{P}_{1} \\
& \mathrm{u}_{\mathrm{en}}=\max \left(16.67, \frac{14 \mathrm{G}(\mathrm{t})}{1+0.0147 \mathrm{G}(\mathrm{t})}-41\right)
\end{aligned}
$$

where $\mathrm{G}(\mathrm{t})[\mathrm{mmol} / \mathrm{L}]$ is the total plasma glucose, $\mathrm{I}(\mathrm{t})[\mathrm{mU} / \mathrm{L}]$ is the plasma insulin and interstitial insulin is represented by $\mathrm{Q}(\mathrm{t})[\mathrm{mU} / \mathrm{L}]$. Exogenous insulin input is represented by $\mathrm{u}_{\mathrm{ex}}(\mathrm{t})$ [mU/min] and endogenous insulin production is estimated with $\mathrm{u}_{\mathrm{en}}[\mathrm{mU} / \mathrm{min}]$, modeled as a function of plasma glucose concentration determined from critical care patients with a minimum pancreatic output of $1 \mathrm{U} / \mathrm{hr} . \mathrm{P}_{1}[\mathrm{mmol}]$ represents the glucose in the stomach and $\mathrm{P}_{2}$ [mmol] represents glucose in the gut. Enteral glucose input is denoted $\mathrm{P}(\mathrm{t})[\mathrm{mmol} / \mathrm{min}]$.

\subsection{Virtual Patients}

Clinically validated virtual trials (Chase et al., 2010b) were carried out using the SPRINT AGC cohort clinical data (Chase et al., 2008b) to create virtual patients. Virtual

\begin{tabular}{|c|c|c|}
\hline $\begin{array}{l}\text { Model } \\
\text { var. }\end{array}$ & Description & $\begin{array}{l}\text { Numerical value } \\
\text { [typical range] }\end{array}$ \\
\hline $\mathrm{p}_{\mathrm{G}}$ & Endogenous glucose clearance & $0.006 \mathrm{~min}^{-1}$ \\
\hline$S_{I}$ & Insulin sensitivity & $\begin{array}{l}{\left[1 \times 10^{-7}-1 \times 10^{-2}\right]} \\
\mathrm{L} /(\mathrm{mU} \cdot \mathrm{min})^{\mathrm{a}}\end{array}$ \\
\hline$\alpha_{\mathrm{G}}$ & $\begin{array}{l}\text { Saturation of insulin-dependent glucose } \\
\text { clearance and receptor-bound insulin } \\
\text { clearance from interstitium }\end{array}$ & $1 / 65 \mathrm{~L} / \mathrm{mU}$ \\
\hline $\mathrm{d}_{1}$ & $\begin{array}{l}\text { Rate of glucose transfer between the } \\
\text { stomach and gut }\end{array}$ & $-\ln (0.5) / 20$ \\
\hline $\mathrm{d}_{2}$ & $\begin{array}{l}\text { Rate of glucose transfer from the gut to } \\
\text { the bloodstream }\end{array}$ & $-\ln (0.5) / 100$ \\
\hline $\mathrm{P}_{\max }$ & Maximum disposal rate from the gut & $6.11 \mathrm{mmol} / \mathrm{min}$ \\
\hline $\mathrm{EGP}_{\mathrm{b}}$ & $\begin{array}{l}\text { Basal endogenous glucose production } \\
\text { (unsuppressed by glucose and insulin } \\
\text { concentration) }\end{array}$ & $\begin{array}{l}1.16 \mathrm{mmol} / \mathrm{min} \\
\text { typically }\end{array}$ \\
\hline $\mathrm{CNS}$ & $\begin{array}{l}\text { Non-insulin mediated glucose uptake by } \\
\text { the central nervous system }\end{array}$ & $0.3 \mathrm{mmol} / \mathrm{min}$ \\
\hline $\mathrm{V}_{\mathrm{G}}$ & Glucose distribution volume & $13.3 \mathrm{~L}$ \\
\hline $\mathrm{n}_{\mathrm{I}}, \mathrm{n}_{\mathrm{C}}$ & $\begin{array}{l}\text { Rate of transport between plasma and } \\
\text { interstitial insulin compartments }\end{array}$ & $0.0075 \mathrm{~min}^{-1}$ \\
\hline$\alpha_{\mathrm{I}}$ & $\begin{array}{l}\text { Saturation of plasma insulin clearance by } \\
\text { the liver }\end{array}$ & $1.7 \times 10^{-3} \mathrm{~L} / \mathrm{mU}$ \\
\hline $\mathrm{V}_{\mathrm{I}}$ & Insulin distribution volume & $4.0 \mathrm{~L}$ \\
\hline $\mathrm{x}_{\mathrm{L}}$ & First-pass hepatic insulin clearance & 0.67 \\
\hline $\mathrm{n}_{\mathrm{K}}$ & $\begin{array}{l}\text { Clearance of insulin from plasma via the } \\
\text { renal route }\end{array}$ & $0.0542 \mathrm{~min}^{-1}$ \\
\hline $\mathrm{n}_{\mathrm{L}}$ & $\begin{array}{l}\text { Clearance of insulin from plasma via the } \\
\text { hepatic route }\end{array}$ & $0.1578 \mathrm{~min}^{-1}$ \\
\hline
\end{tabular}
patients are created using clinical data to identify an hourly treatment-independent insulin sensitivity profile $S_{I}(t)$ (Hann et al., 2005), allowing virtual trials to realistically simulate
TABLE I

CONSTANTS USED IN SYSTEM MODEL OF EQUATIONS (1)-(6)

${ }^{\mathrm{a}}$ Insulin sensitivity (SI) is identified from clinical data in the range shown.

patient response to a given (modified) treatment. This approach has been clinically validated on independent matched cohort data (Chase et al., 2010b) and in several AGC trials (Penning et al., 2011, Evans et al., 2011). Patient demographics are given in Table II.

Patients were considered to require AGC once $\mathrm{BG}>$ $7.0 \mathrm{mmol} / \mathrm{L}$, and this value was used to determine the beginning of a virtual trial. Interruptions in nutrition are common for some patients in clinical practice, and are incorporated by setting $\mathrm{P}(\mathrm{t})=0 \mathrm{mmol} / \mathrm{min}$ over the same periods they occurred in the clinical data. Equally, clinically specified parenteral nutrition (PN) was included in the simulations just as it was given clinically.

\subsection{Stochastic Control Method}

STAR provides patient-specific treatment in real time. Stochastic forecasting provides a framework for control of future outcomes, particularly the mitigation of mild, moderate, and severe hypoglycemia. STAR was also developed with the intent to use the simplest, most

TABLE II

PATIENT DEMOGRAPHICS

\begin{tabular}{lc}
\hline \hline & SPRINT cohort \\
\hline Total patients & 371 \\
Age (years) & $65[49-74]$ \\
$\%$ Male & $63.6 \%$ \\
APACHE II score & $18[15-24]$ \\
APACHE II risk of death & $25.7 \%[13.1 \%-49.4 \%]$ \\
Diabetic history & $62(16.7 \%)$ \\
\end{tabular}


transparent control logic (Chase et al., 2008a). This latter aspect had the goal of ensuring its choices were as understandable as possible, and thus directly translated into safe, effective and clinically acceptable treatment recommendations to maximize compliance.

When a BG measurement is entered, the model is used to evaluate current patient insulin sensitivity (Hann et al., 2005) and its likely variation (Lin et al., 2008) over the next 1 to 3 hours. Insulin is administered in bolus form for safety from unintended delays (Lonergan et al., 2006). However, infusions may also be used. Robustness to glucometer measurement error limits increases in insulin rate to $+2 \mathrm{U} /$ hour, with upper limits on the total bolus dose $(6 \mathrm{U} / \mathrm{hr})$ and any added infusion rate for highly resistant patients ( $3 \mathrm{U} / \mathrm{hr}$ ). Thus, total insulin is limited to $9 \mathrm{U} / \mathrm{hr}$. Insulin can be reduced to $0 \mathrm{U} / \mathrm{hr}$ from any rate if required. Enteral nutrition is controlled between $30-100 \%$ of ACCP goal (Cerra et al., 1997 ), and changes are limited to $\pm 30 \%$ per intervention cycle. However, nutrition administration can be set to a fixed constant rate or zero if clinically specified.

Measurement or treatment interval is specifically limited when: 1) current measured BG is outside the specified target range of $80-145 \mathrm{mg} / \mathrm{dL}$ (1-hourly limits); or 2) the patient is unable to be fed (2-hourly maximum interval). Otherwise, when the current measured BG is within the clinically specified target range, STAR calculates intervention options (insulin and nutrition) for 1,2 and 3 hourly measurement intervals, and nurses choose from these intervals.

For each allowed insulin/nutrition combination and treatment interval based on the limits specified, stochastic forecasts are generated for the predicted 5th percentile of BG outcomes (Figure 1, points A, B and C) and the predicted 95th percentile of BG outcomes (Figure 1, points D, E and F). For all treatment intervals, glycemic level is controlled by targeting the 5th percentile of BG outcomes to the lower limit of the desired range including tolerance $(80-85 \mathrm{mg} / \mathrm{dL})$. Hypoglycemia is thus directly managed as insulin rates cannot be recommended if the predicted 5th percentile is below this limit. The tolerance on the lower limit ensures consistent interventions between measurement intervals offered (1, 2 and 3-hourly). The 5th percentile target is prioritized for control due to the skewed nature of the $\mathrm{BG}$ outcome distribution, as depicted in Figure 1, which ensures BG outcomes best overlap the lower $(80-125 \mathrm{mg} / \mathrm{dL})$ desired portion of the $80-145 \mathrm{mg} / \mathrm{dL}$ range. This $80-125 \mathrm{mg} / \mathrm{dL}$ range is associated with better outcomes (Egi et al., 2006, Van den Berghe et al., 2001) and is also associated with reduced rate and severity of organ failure (Chase et al., 2010a).

Tightness of the AGC provided by STAR is thus determined by the treatment of the 95th percentile forecast outcomes. This upper limit is used to restrict treatment interval only if a desired 2- or 3- hourly treatment allows $95^{\text {th }}$ percentile BG above the target range. Monitoring the likelihood of predicted BG outcome, as shown in Figure 1, allows for more explicit direct control over intra-patient variability and therefore directly limits the risk and occurrence of mild hyperglycemia. Hourly measurements are always offered, regardless of the

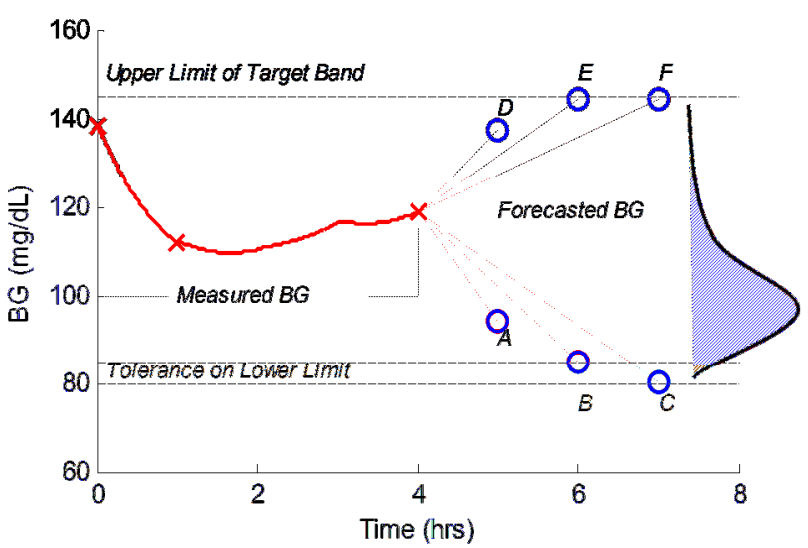

Fig.1. Controller forecast schematic for BG a target range of 80 $145 \mathrm{mg} / \mathrm{dL}$. A BG measurement has been taken at $10 \mathrm{hrs}$, and forecasts of BG have been generated (points A-F). The depicted distribution indicates the skewed nature of BG forecasts within the 5th-95th percentiles.

95th percentile forecast. If the 5th percentile BG is forecast to be within tolerance of the target band lower limit the treatment is considered acceptable. For cases where the forecast $\mathrm{BG}$ range does not meet this criteria there are two possibilities. If the $95^{\text {th }}$ percentile BG is forecast below the upper limit of the target band hyperglycemia is satisfactorily controlled, and the insulin/nutrition combination is considered acceptable. Otherwise, neither hyper- or hypoglycemia is satisfactorily controlled and the combination is not permitted.

STAR maximizes performance (time in glycemic bands) with a minimum, clinically specified risk of mild hypoglycemia ( $5 \%$ for $\mathrm{BG}<80 \mathrm{mg} / \mathrm{dL}, \approx 1 \%$ for $\mathrm{BG}<72 \mathrm{mg} / \mathrm{dL}$ ). Within this goal, the control determines the allowable insulin/nutrition combinations. Importance is placed on maximizing nutrition rates (Alberda et al., 2009), particularly for longer stay patients, but not at the risk of exacerbating hyperglycemia. Hence, STAR ranks allowable treatments by nutrition rate, ensuring the treatment with the highest enteral nutrition rate is selected.

The longest measurement intervals are calculated first. If an acceptable treatment is found, the selected nutrition rate is used as a lower limit for shorter treatment intervals. This approach ensures treatment consistency across all intervention and measurement intervals to maximize transparency and clinical acceptance, and thus compliance (Chase et al., 2008a). Specifically, it ensures an intuitive combination of treatment options, where longer measurement intervals also generally yield wider stochastic forecasting bounds and thus more conservative (lower insulin) treatment choices.

\subsection{Virtual Trials}

Virtual trials were carried out to verify performance before clinical testing. STAR is simulated in two forms: a) maximum measurement interval available is chosen ("STAR - Max"); and b) select at maximum 2-hourly intervals when available ("STAR 2-hourly") to best compare with SPRINT, which had a 2-hourly maximum interval. Results were compared to clinical SPRINT data to demonstrate 
improvements in performance and safety over the currently utilized SPRINT protocol that successfully reduced mortality (Chase et al., 2008b) and organ failure (Chase et al., 2010a).

\subsection{Analyses/Performance Metrics}

Performance was defined as percentage of BG within selected glycemic bands. Clinical effort is evaluated by BG measurement frequency as a surrogate (Mackenzie et al., 2005, Aragon, 2006). Safety was defined as the incidence of severe (number patients with $\mathrm{BG}<40 \mathrm{mg} / \mathrm{dL}$ ) and mild $(\% \mathrm{BG}<72 \mathrm{mg} / \mathrm{dL})$ hypoglycemia. All BG data was resampled hourly to provide a consistent time-basis for comparison across protocols with different measurement and intervention intervals.

Finally, the virtual trial approach is further validated in comparison to results for the first 10 patients in initial STAR pilot clinical trials (1458 hours, $70 \%$ male, median age of 67 [51-70], APACHE II score of 27.5 [19-30], risk of death of $52 \%$ [31\%-60\%], and total mortality of $30 \%$ ). All patients were treated for length of stay after informed consent was obtained. Approval for this study and use of the data was given by the Upper South A Ethics Committee (URA/10/09/069).

\section{RESULTS}

Table III shows both versions of STAR reduce the number of cases of severe hypoglycemia and more than halve the measures of mild hypoglycemia compared to SPRINT. There is a $79 \%$ reduction in severe hypoglycemia between STAR 2hourly and SPRINT showing the importance of the STAR approach independent of measurement interval, as both protocols have a 2-hour maximum interval and similar measurements per day. These safety gains are introduced with reduced clinical effort of 11.8 and 14.9 measures/day compared to 16.1 for SPRINT, and with equivalent or higher time in desired glycemic bands. Importantly, median nutrition rates are raised by $32 \%$ (absolute) of ACCP goal rate. Thus, all indications show STAR will provide global improvements over SPRINT in performance, safety and effort when applied clinically.

Figures 2 and 3 display major behavioral differences between STAR and SPRINT. Each figure categorizes the insulin/nutrition combination selected to display relative frequency. Figure 2 indicates the preferred behavior of STAR is to modulate insulin at a higher nutrition rate, while Figure 3 indicates SPRINT typically modulates nutrition at moderate, relatively constant insulin administration levels. This difference implies a clinical advantage when high nutrition input is preferred. It equally highlights that insulin dosage behavior is relative to carbohydrate input, showing importance of accounting for nutrition in AGC, which many published protocols do not [34]. Finally, and equally importantly, the most common outcome in Figure 2 is $100 \%$ goal feed and $0 \mathrm{U} / \mathrm{hr}$ ( $11 \%$ of total interventions $=1$ in 9$)$, a safe and effective outcome enabled by the STAR framework's stochastic model-based approach that was not possible with SPRINT.
TABLE III

STAR VS. SPRINT FULL COHORT SIMULATION RESULTS

\begin{tabular}{|c|c|c|c|c|}
\hline $\begin{array}{l}\text { Whole cohort } \\
\text { statistics }\end{array}$ & $\begin{array}{l}\text { STAR - } \\
\text { Max }\end{array}$ & $\begin{array}{l}\text { STAR 2- } \\
\text { hourly }\end{array}$ & $\begin{array}{c}\text { SPRINT } \\
\text { Data }\end{array}$ & $\begin{array}{l}\text { STAR } \\
\text { clinical } \\
\text { data }\end{array}$ \\
\hline \# patients: & 371 & 371 & 371 & 10 \\
\hline Total hours: & 40101 & 40006 & 39841 & 1486 \\
\hline \# BG measures: & 19634 & 24218 & 26646 & 836 \\
\hline Measures/day & 11.8 & 14.9 & 16.1 & 13.5 \\
\hline BG median & 109 & 109 & 101 & 109 \\
\hline $\begin{array}{l}{[\mathrm{IQR}](\mathrm{mg} / \mathrm{dL}) \text { : }} \\
\text { Normoglycemia: }\end{array}$ & [100-120] & [100-119] & [90-115] & [99-122] \\
\hline $\begin{array}{l}\% \mathrm{BG} \text { in } 80- \\
125 \mathrm{mg} / \mathrm{dL} \\
\% \mathrm{BG} \text { in } 80-\end{array}$ & 81.0 & 82.5 & 78.5 & 78.2 \\
\hline $\begin{array}{l}145 \mathrm{mg} / \mathrm{dL} \\
\text { Hyperglycemia: }\end{array}$ & 91.6 & 92.1 & 86.0 & 89.4 \\
\hline $\begin{array}{l}\% \mathrm{BG} \text { in } 145- \\
180 \mathrm{mg} / \mathrm{dL} \\
\% \mathrm{BG}>\end{array}$ & 4.69 & 4.59 & 4.45 & 5.63 \\
\hline $\begin{array}{l}180 \mathrm{mg} / \mathrm{dL} \\
\text { Safety: }\end{array}$ & 1.65 & 1.64 & 2.00 & 2.48 \\
\hline$\% \mathrm{BG}<80 \mathrm{mg} / \mathrm{dL}$ & 2.06 & 1.69 & 7.83 & 2.48 \\
\hline $\begin{array}{l}\% \mathrm{BG}<72 \mathrm{mg} / \mathrm{dL} \\
\text { \# patients }<\end{array}$ & 0.83 & 0.70 & 2.89 & 1.54 \\
\hline $\begin{array}{l}40 \mathrm{mg} / \mathrm{dL} \\
\text { Interventions: }\end{array}$ & 4 & 3 & 14 & 0 \\
\hline Median insulin & 2.5 & 2.5 & 3.0 & 3.0 \\
\hline rate [IQR] $(\mathrm{U} / \mathrm{hr})$ : & {$[1.5-4.0]$} & {$[1.5-4.0]$} & {$[2.0-4.0]$} & {$[1.4-4.5]$} \\
\hline Median glucose & 5.0 & 5.1 & 4.1 & 4.9 \\
\hline $\begin{array}{l}\text { rate }[\mathrm{IQR}](\mathrm{g} / \mathrm{hr}) \text { : } \\
\text { Median glucose }\end{array}$ & {$[2.2-6.4]$} & {$[2.3-6.5]$} & {$[1.9-5.6]$} & {$[0.0-6.1]$} \\
\hline rate [IQR] $(\%$ & 90.0 & 90.0 & 68.1 & 80.0 \\
\hline goal): & {$[30-100]$} & [30-100] & {$[30-85]$} & [0.0-109] \\
\hline
\end{tabular}

STAR

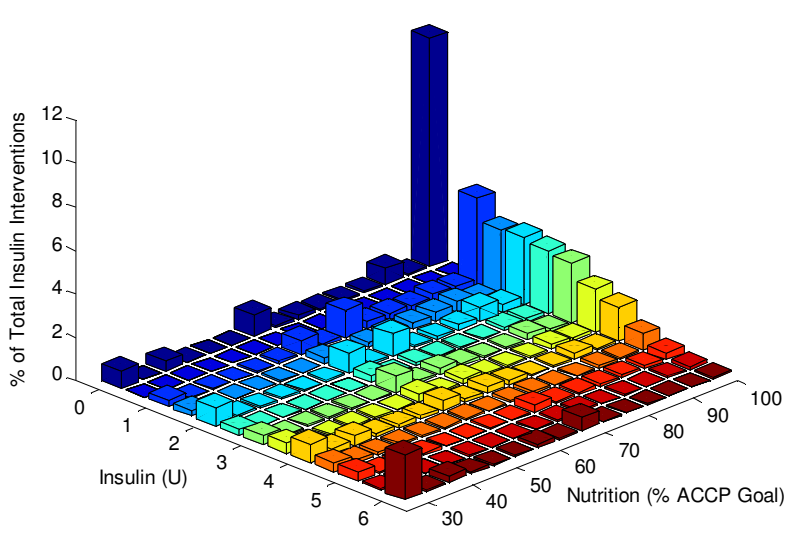

Fig.2. STAR Nutrition/Insulin Combination Frequency

SPRINT Clinical Data

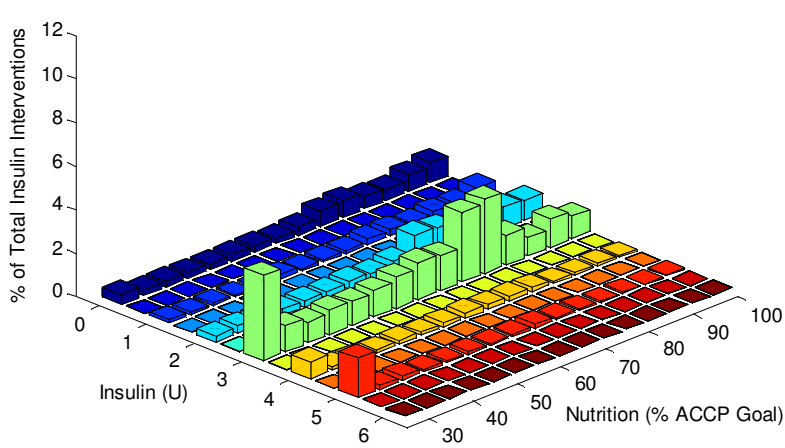

Fig.3. SPRINT Nutrition/Insulin Combination Frequency 
The simulation results are supported by the initial pilot trial results presented in Figure 4 for the first 10 patients. The clinical BG results (Table III) are very similar to simulation results with $89.4 \%$ of $\mathrm{BG}$ within $80-145 \mathrm{mg} / \mathrm{dL}$ and $78.2 \%$ BG within $80-125 \mathrm{mg} / \mathrm{dL}$. Safety has been maintained with $1.54 \%$ of $\mathrm{BG}<72 \mathrm{mg} / \mathrm{dL}$ and no severe hypoglycemia events $(\mathrm{BG}<40 \mathrm{mg} / \mathrm{dL})$. Median BG was 109mg/dL [IQR: 99.5-122 $\mathrm{mg} / \mathrm{dL}]$, which matches very closely with the location and spread of BG in virtual trials.

\section{DISCUSSION}

STAR virtual trials demonstrate safe, effective AGC in a clinically applicable fashion. Significant safety improvements would be likely compared to the current generation of BG control in Christchurch Hospital (SPRINT), which was the safest published protocol targeting $\mathrm{BG} \leq 110 \mathrm{mg} / \mathrm{dL}$. Most significantly, only 4 patients out of 371 (1.1\% by patient and a reduction of $71 \%$ from SPRINT) showed severe hypoglycemia, and, in all cases, this hypoglycemia was quickly resolved. Clinical applicability is strongly supported by the initial pilot results, with both the performance and safety benefits seen in virtual trials being realized in practice.

The relatively higher enteral nutrition rate for STAR compared to SPRINT is likely to increase clinical acceptance. Higher feed is generally preferred in many cases (Alberda et al., 2009), despite some recent contradictory evidence (Casaer et al., 2011, Krishnan et al., 2003). However, STAR can be easily adjusted by setting nutrition administration goals to match any emerging evidence, and insulin rates will automatically modify to maintain glycemic balance.

The comparison between STAR-Max and STAR 2-hourly illustrates a known trade-off between measurement rate (nursing workload) and patient safety. However, both provide quality AGC. Thus, the main impact of measurement interval in the STAR framework is on safety from intra-patient variability.

Equally importantly, the ability of nursing staff to choose between measurement interval options means that an informed decision can be made at each BG reading. Thus, nurses self-manage this workload. This choice or feature is expected to also have a positive impact on compliance and

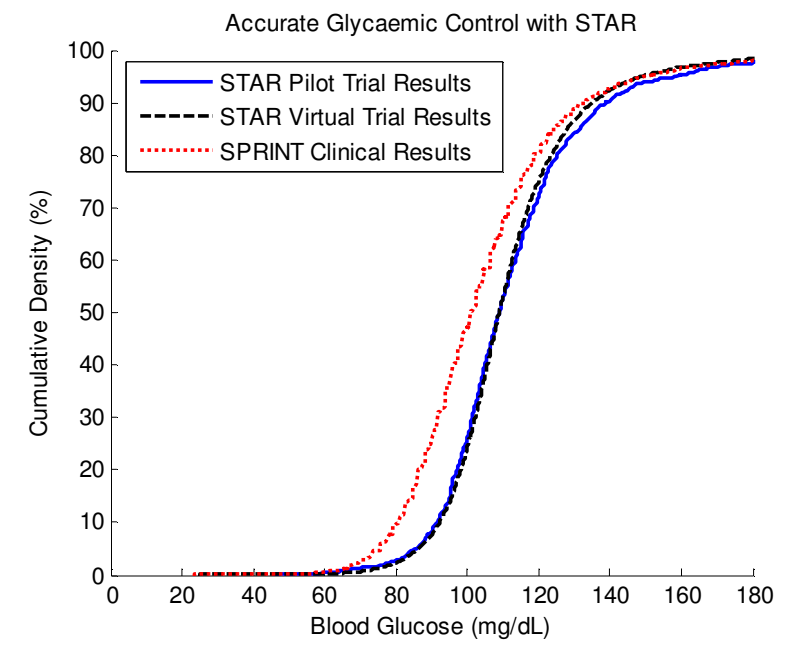

Fig.4. Cumulative density plot of current pilot trial results against simulation results and SPRINT clinical data after 10 patients. acceptance.

A notable enhancement of the model-based approach of STAR compared to the fixed approach in SPRINT is the ability to change the desired target range and other factors or limits. This ability has implications for the balance between workload, safety and nutrition. For example, raising the target $\mathrm{BG}$ range could provide increased nutrition intake at the expense of higher BG. Providing a wider target band may allow reduced workload with fewer BG measurements under the target-to-range scheme presented, but may result in increased glycemic variability within that band for which the clinical outcomes are not fully known. These decisions can be made by the attending clinical team based on their goals for a particular patient and assessment of current evidence. Hence, the framework can be directly and easily adopted and generalized to any clinical culture and practice, unlike previously published protocols.

More importantly perhaps, STAR can thus provide the power to automatically balance the clinical treatment, based on clinical goals for each patient. It thus avoids forcing a clinicwide target or approach onto patients who have requirements outside the norm, or subjecting them to ad-hoc decisions to handle their particular cases. Thus, for example, different BG target ranges could be readily specified for different clinical conditions based on diagnosis and this target range could be updated as treatment progresses.

\section{CONCLUSIONS}

AGC requires accounting for patient metabolic variability while balancing safety and workload requirements. In-silico results indicate the developed STAR algorithm provides a safe and effective method for management of glycemia. The model-based nature of STAR allows easy adjustment of BG and nutrition to match emerging clinical evidence, and permits individualization of treatment goals to particular patient outcomes. Finally, the overall framework presented is unique in its stochastic, risk-based approach, as well as completely generalizable.

\section{REFERENCES}

ALBERDA, C., GRAMLICH, L., JONES, N., JEEJEEBHOY, K., DAY, A. G., DHALIWAL, R. \& HEYLAND, D. K. 2009. The relationship between nutritional intake and clinical outcomes in critically ill patients: results of an international multicenter observational study. Intensive Care Med, 35, 1728-37.

ARAGON, D. 2006. Evaluation of nursing work effort and perceptions about blood glucose testing in tight glycemic control. Am J Crit Care, 15, 370-7.

BAGSHAW, S., BELLOMO, R., JACKA, M., EGI, M., HART, G., GEORGE, C. \& COMMITTEE, T. A. C. M. 2009. The impact of early hypoglycemia and blood glucose variability on outcome in critical illness. Critical Care, 13, R91.

CASAER, M. P., MESOTTEN, D., HERMANS, G., WOUTERS, P. J., SCHETZ, M., MEYFROIDT, G., VAN CROMPHAUT, S., INGELS, C., MEERSSEMAN, P., MULLER, J., 
VLASSELAERS, D., DEBAVEYE, Y., DESMET, L., DUBOIS, J., VAN ASSCHE, A., VANDERHEYDEN, S., WILMER, A. \& VAN DEN BERGHE, G. 2011. Early versus late parenteral nutrition in critically ill adults. $N$ Engl $J$ Med, 365, 506-17.

CERRA, F. B., BENITEZ, M. R., BLACKBURN, G. L., IRWIN, R. S., JEEJEEBHOY, K., KATZ, D. P., PINGLETON, S. K., POMPOSELLI, J., ROMBEAU, J. L., SHRONTS, E., WOLFE, R. R. \& ZALOGA, G. P. 1997. Applied nutrition in ICU patients. A consensus statement of the American College of Chest Physicians. Chest, 111, 769-78.

CHASE, J. G., ANDREASSEN, S., JENSEN, K. \& SHAW, G. M. 2008a. Impact of Human Factors on Clinical Protocol Performance: A Proposed Assessment Framework and Case Examples. Journal of Diabetes Science and Technology, 2, 409-416.

CHASE, J. G., LE COMPTE, A. J., SUHAIMI, F., SHAW, G. M., LYNN, A., LIN, J., PRETTY, C. G., RAZAK, N., PARENTE, J. D., HANN, C. E., PREISER, J.-C. \& DESAIVE, T. 2011. Tight glycemic control in critical care - The leading role of insulin sensitivity and patient variability: A review and model-based analysis. Computer Methods and Programs in Biomedicine, 102, 156-171.

CHASE, J. G., PRETTY, C. G., PFEIFER, L., SHAW, G. M., PREISER, J. C., LE COMPTE, A. J., LIN, J., HEWETT, D., MOORHEAD, K. T. \& DESAIVE, T. 2010a. Organ failure and tight glycemic control in the SPRINT study. Crit Care, 14, R154.

CHASE, J. G., SHAW, G., LE COMPTE, A., LONERGAN, T., WILLACY, M., WONG, X.-W., LIN, J., LOTZ, T., LEE, D. \& HANN, C. 2008b. Implementation and evaluation of the SPRINT protocol for tight glycaemic control in critically ill patients: a clinical practice change. Critical Care, 12, R49.

CHASE, J. G., SUHAIMI, F., PENNING, S., PREISER, J. C., LE COMPTE, A. J., LIN, J., PRETTY, C. G., SHAW, G. M., MOORHEAD, K. T. \& DESAIVE, T. 2010b. Validation of a model-based virtual trials method for tight glycemic control in intensive care. Biomed Eng Online, 9, 84.

EGI, M., BELLOMO, R., STACHOWSKI, E., FRENCH, C. J. \& HART, G. 2006. Variability of blood glucose concentration and short-term mortality in critically ill patients. Anesthesiology, 105, 244-52.

EVANS, A., SHAW, G. M., LE COMPTE, A., TAN, C. S., WARD, L., STEEL, J., PRETTY, C. G., PFEIFER, L., PENNING, S., SUHAIMI, F., SIGNAL, M., DESAIVE, T. \& CHASE, J. G. 2011. Pilot proof of concept clinical trials of Stochastic Targeted (STAR) glycemic control. Ann Intensive Care, 1, 38.

GRIESDALE, D. E., DE SOUZA, R. J., VAN DAM, R. M., HEYLAND, D. K., COOK, D. J., MALHOTRA, A., DHALIWAL, R., HENDERSON, W. R., CHITTOCK, D. R., FINFER, S. \& TALMOR, D. 2009. Intensive insulin therapy and mortality among critically ill patients: a meta-analysis including NICE-SUGAR study data. CMAJ, 180, 821-7.

HANN, C. E., CHASE, J. G., LIN, J., LOTZ, T., DORAN, C. V. \& SHAW, G. M. 2005. Integral-based parameter identification for long-term dynamic verification of a glucose-insulin system model. Comput Methods Programs Biomed, 77, 259-270.

KRINSLEY, J. S. 2004. Effect of an intensive glucose management protocol on the mortality of critically ill adult patients. Mayo Clin Proc, 79, 992-1000.

KRINSLEY, J. S. 2008. Glycemic variability: a strong independent predictor of mortality in critically ill patients. Crit Care Med, 36, 3008-13.

KRISHNAN, J. A., PARCE, P. B., MARTINEZ, A., DIETTE, G. B. \& BROWER, R. G. 2003. Caloric intake in medical ICU patients: consistency of care with guidelines and relationship to clinical outcomes. Chest, 124, 297-305.

LIN, J., LEE, D., CHASE, J. G., SHAW, G. M., LE COMPTE, A., LOTZ, T., WONG, J., LONERGAN, T. \& HANN, C. E. 2008. Stochastic modelling of insulin sensitivity and adaptive glycemic control for critical care. Computer Methods and Programs in Biomedicine, 89, 141-152.

LIN, J., RAZAK, N. N., PRETTY, C. G., LE COMPTE, A., DOCHERTY, P., PARENTE, J. D., SHAW, G. M., HANN, C. E. \& GEOFFREY CHASE, J. 2011. A physiological Intensive Control Insulin-NutritionGlucose (ICING) model validated in critically ill patients. Comput Methods Programs Biomed, 102, 192-205.

LONERGAN, T., LECOMPTE, A., WILLACY, M., CHASE, J. G., SHAW, G. M., WONG, X. W., LOTZ, T., LIN, J. \& HANN, C. E. 2006. A simple insulin-nutrition protocol for tight glycemic control in critical illness: development and protocol comparison. Diabetes Technol Ther, 8, 191-206.

MACKENZIE, I., INGLE, S., ZAIDI, S. \& BUCZASKI, S. 2005. Tight glycaemic control: a survey of intensive care practice in large English hospitals. Intensive Care Med, 31, 1136.

MCCOWEN, K. C., MALHOTRA, A. \& BISTRIAN, B. R. 2001. Stress-induced hyperglycemia. Crit Care Clin, 17, 107-124.

PENNING, S., LE COMPTE, A. J., MOORHEAD, K. T., DESAIVE, T., MASSION, P., PREISER, J. C., SHAW, G. M. \& CHASE, J. G. 2011. First pilot trial of the STAR-Liege protocol for tight glycemic control in critically ill patients. Comput Methods Programs Biomed.

VAN DEN BERGHE, G., WOUTERS, P., WEEKERS, F., VERWAEST, C., BRUYNINCKX, F., SCHETZ, M., VLASSELAERS, D., FERDINANDE, P., LAUWERS, P. \& BOUILLON, R. 2001. Intensive insulin therapy in the critically ill patients. $N$ Engl $J$ Med, 345, 1359-1367. 